\title{
Public Reasoning Around Social Contention: A Case Study of Twitter Use in the Italian Mobilization for Global Change
}

Stefania Vicari, sv32@le.ac.uk, University of Leicester, Department of Media and Communication

Bio: Stefania Vicari is a lecturer in Media and Communication at the University of Leicester. She holds a Ph.D. in Sociology from the University of Reading, an MA in Globalization and Communications from the University of Leicester, and a Laurea in Communication Sciences from the University of Turin. Prior to her current position she was a visiting scholar at Emory University and a lecturer in Sociology of Communication at the University of Sassari. Her most recent publications include the book chapters "Twitter and public reasoning around social contention: The case of \#15ott in Italy" (2012) and "Investigating Facebook walls: A quantitative approach to online community building" (2011), and the journal articles "Measuring collective action frames: A linguistic approach to frame analysis" (Poetics, 2010) and "Relazioni locali, nodi digitali e reti transnazionali di protesta" (Polis XX, 2006). Her research interests include the general areas of social movements, online mobilization, and public reasoning around social contention.

\begin{abstract}
Social media have become central to organizational and logistic dynamics in contemporary social contention. Not only have they eased centralized processes of information sharing between social movement entrepreneurs and social movement publics, they have also bolstered the crowdsourced management of public discussion around social contention. This article investigates the use of social media for public reasoning around issues related to social contention. By investigating Twitter streams with reference to the Italian chapter of the October 15, 2011 polycentric protest for Global Change, this study specifically addresses the use of Twitter in the aftermath of protest events of high impact for the general public. The quantitative analysis of longitudinal progression, networking mechanisms, and processes of meaning construction in over 8,000 tweets shows that Twitter does bolster public reasoning around social contention. It does so as a news medium rather than a conversational platform, primarily providing a space to share information alternative to that available in mainstream media coverage.
\end{abstract}

Keywords: opinion formation, protest, public reasoning, Twitter.

\section{Introduction}

The recent mobilizations for social and economic justice have staged several global days of 
action where networked activist groups engaged in national and local demonstrations. When compared to the early twenty-first century mobilization for global justice, today's transnational activism is new in two aspects: the current socio-political background marked by the global economic crisis, and the use of social media in general and micro-blogging platforms in particular, to spread information, coordinate protest activities, debate on protest issues, and counter, integrate or disseminate mass media coverage of protest events (Howard et al., 2011; Segerberg and Bennett, 2011).

As part of the current wave of transnational activism for social and economic justice, on October 15, 2011 protestors took to the streets of over eighty countries to demand changes in the global economic system. The Italian involvement in this global day of action is particular interesting for two main reasons. First, Italy was the only country where the October 15, 2011 global protest resulted in violent events, with street destructions perpetuated by several hundreds of activists and clashes between protesters and the police. This certainly bolstered the emergence of public reasoning on the protest during and after the events. Second, in 2011 Italy had the highest micro-blog penetration in Europe, with Twitter being by far the most popular micro-blogging service (GlobalWebIndex, 2011).

By applying a case study approach, the present work aims to investigate the role of Twitter in the public discussion emerging after protest events of high impact for the general public. The study explores the most prominent hashtag in the Italian demonstrations on October 15: \#15Ott. The analysis focuses on over 8,000 tweets produced in the thirty days following the protest: from the mid-morning of October 16 until the morning of November $15,2011$.

Findings show that Twitter can become a platform for public reasoning around mobilization and social contention. However, it does so by bolstering news media rather than conversational processes: it provides an additional space to share information alternative to that available in mainstream media coverage but it does not bolster diffused dialogical processes. The study also shows that news values in the coverage of contemporary social protest are now defined by both mainstream and social media.

\section{Local Levels}

1.2. The 15 October Polycentric Protest for Global Change: Transnational and

The October 15 polycentric protest for Global Change was launched in late August 2011. Two transnational collective actors first promoted the call for action: the Indignados coalition and the Occupy Wall Street (OWS) Movement, later to be renamed the Occupy Movement. The former, emerged in Spain in May 2011, had already spread in several European countries particularly affected by the economic crisis (namely, Greece, Portugal, and Italy). The latter was about to take "the square" ii . Those collective actors shared at least two main attributes: they drew inspiration from the Arab spring (i.e., the uprisings in Tunisia, Egypt, Libya, 
Yemen, and Syria) and they mobilized - in broad terms - against economic inequality.

The mobilization of the October 15 polycentric protest for Global Change was first publicly launched online via independent (e.g. n-1.cc) and mainstream social media. On Facebook, together with the multilingual event '15.O International Mobilization: \#globaldemocracy' several monolingual events (e.g. the French 'Révolution Mondiale pour une Réelle Démocratie', the Spanish 'Revolución global: Democracia real YA', and the German 'Echte Demokratie Jetzt') and communities (e.g. the Italian '15 ottobre: un milione di indignati in corteo verso il parlamento') were created to mobilize demonstrations at national and city levels. Clips launching and promoting the call for action were posted on Youtube and Vimeo video sharing social networks. Twitter streams with reference to the protest emerged in late August 2011 and grew exponentially a few days before October 15 to further develop during and after the protest. Several hashtags were used to build Twitter streams relevant to the demonstrations, from those formerly implemented to discuss issues relevant to the Occupy Movement (e.g., \#occupywallstreet and \#ows) to the new ones more closely concerned with the October 15 demonstrations (i.e., \#15o and \#15oct).

According to activists' records, the October 15 polycentric protest for Global Change took place in over 1,000 cities around the world (15october.net: 2011). In Italy, activists organized demonstrations in over 20 cities with the biggest event taking place in Rome. There, around 200,000 people participated in the protest (15october.net: 2011). The Rome demonstration was primarily organized and mobilized by the so-called 'Coordinamento 15 ottobre', a coalition endorsed by leftist political parties, social movement organizations (among which was the leading Popolo Viola ${ }^{\text {iii }}$ ), and trade unions. Coordinamento 15 ottobre planned a march in the heart of the city. On the afternoon, part of the activists involved in the rally turned violent while hooded protesters, later to be loosely identified as Black Block ${ }^{\text {iv }}$, set the city on fire. Cars, shop windows, bank entrances and police vans became the main targets of destruction while clashes between protesters and the police occurred in several locations, resulting in over 100 injured people (Corriere della Sera.it: 2011). According to a communiqué released by the press office of Rome City Council on November 14, 2011, the damage from the rioting amounted to $€ 900,000$. According to mass media and activists' records, the protest only turned violent in the city of Rome.

\section{Theoretical Background}

\subsection{Public Reasoning Around Social Contention}

Early literature on the media coverage of protest action drew attention to the "dominant law and (dis)order frame" (Cottle, 2011: 21) often used by national news media to report on domestic protests and demonstrations. In this scenario, public reasoning on social contention was very much centered on the discussion of sensational elements of protest performance, like violence, drama, and spectacle. Early empirical studies, for instance, highlighted the 
emergence of media frames of violence (Halloran et al., 1970; Murdock, 1981) and highly polarized media discourses (Gitlin, 1980) in the coverage of major protest events taking place in the 1960s. More recently, Waddington also showed how national media coverage has constantly polarized the definition of domestic protest and protest events, while backgrounding, distorting and oversimplifying protest causes (1992: 175-6). At the core of these studies lies the idea that media frames and discourses around domestic social contention very often shift public attention - and public reasoning - from protest causes to protest forms of action, undermining the development of a bottom-up, open, and reasoned debate on protest ideas and rationales (see also Cottle, 2006: 39). In this framework, mainstream media prevent the emergence of a well-informed public opinion, that is, a healthy public sphere debating on dissent and contested social issues. In fact, until the 1990s the only challenges to mainstream media representations of protest and protest events would come from alternative or radical media. Yet, these media outlets have always lacked "audience, professionalism and finance" (Downey and Fenton, 2003: 196) and have proved unsuccessful in countering the influence of mainstream media on the general public.

For the past twenty years, both media and social movement literatures have started expanding their focus on the mediatization of social contention, by taking into account the changing features of the contemporary media ecology. In particular, attention has been drawn to the potential of new ICTs in easing the delivery of alternative representations of social contention. The leading argument here is that actors from outside the traditional news media system can now cover protest issues neglected by the mainstream media and easily reach expanded audiences. From this perspective, the characteristics of the Internet infrastructure in terms of access and availability - can enhance the emergence of new platforms for deliberative democracy, that is, new spaces for public reasoning around social contention. The Zapatista Internet political activism emerged in 1994 has been studied as the first example of "counter-publicity" (Downey and Fenton, 2003: 196) able to both impact the public sphere in Mexico and reach out to an international public (Castells, 1996; Garrido and Halavais, 2003: 166; Villarreal Ford and Gil, 2001: 226). This early example of online protest self-coverage has been followed by the development of new media networks, e.g., blogospheres, BBS, and discussion sites (Cottle 2006: 51). The so-called "Battle of Seattle" - the 1999 demonstration against the World Trade Organisation - for instance, saw the emergence of the Independent Media Centre (Indymedia), a media website network set up to provide a coverage of the events alternative to that made available by corporate-controlled media (Langman 2005: 55) ${ }^{\mathrm{v}}$. These two examples - Zapatista Internet activism and Indymedia - are representative of the contemporary shift in public reasoning around social contention, where the top-down management of protest medatization is successfully countered by online participatory processes.

At the core of the current debates on if and how new media may open up new ways for deliberative democracy and public sphere(s) we now find an emerging literature looking at 
social media as the most contemporary setting for public reasoning around social contention. The focus is on micro-blogging services, with Twitter seen as the most successful microblogging platform in the Western world. On Twitter, one can post short messages (of up to 140 characters) that can be read by any other user. Twitter users may follow other users, meaning that they are notified when these other users post a new message. However, as Huberman et al. suggest, in Twitter "the driver of usage is a sparse and hidden network of connections underlying the "declared" set of friends and followers" (2009). In fact, Twitter enables further networking dynamics via three specific practices: participants can address their messages - tweets - to other users by using the "@user" syntax, they can mark tweets topically by adding hashtags (\#s) that generate Twitter streams centered on specific topics, and they can retweet older tweets, namely re-post tweets already posted by other users.

Twitter streams cut across the users' own offline social networks. However, the question of how such networking mechanisms work in terms of network cohesion and reciprocity is still open. Kwack and colleagues (2010) showed that Twitter streams relevant to social contention have high homophily and little reciprocity, i.e., Twitter players tend to communicate with other players with similar opinions and overall dialogical interactions are very rare. In this sense, Twitter seems more likely to become a news medium than a social network as such. Moreover, the classification of trending topics shows that the majority of topics "are headline or persistent news in nature" (Kwak et al., 2010: 10). Hence, these findings suggest that Twitter streams are likely to lack strong interactional patterns but can become channels for alternative information sharing within online active audiences.

The present study aims to address the question of how public reasoning around social contention may develop in contemporary micro-blogging settings. More specifically: does micro-blogging on social contention cut across the protest ecology involving different actors in the debate? Do actors involved in the protest public debate engage in consensus/contestation dynamics via conversational practices? How do protest issues covered on micro-blogging platforms relate to those made available on traditional news media?

\section{Data and Methods}

Recent empirical studies on the use of Twitter in relation to social contention have started tackling the problem of analyzing Twitter streams (see Bajpai and Jaiswal 2011; Segerberg and Bennet 2011; Procter and Vis 2011). The present study applies a mixed-method approach to the Italian \#15Ott hashtagged Twitter stream, specifically focusing on four aspects of Twitter usage: the positioning of the Italian \#15Ott stream among other streams relevant to the protest (i.e., was the national \#15Ott stream used in the same way as the corresponding international streams?); tweeting dynamics over time (i.e., how did the stream evolve?); players, networking structures and news media processes (i.e., who tweeted? what was tweeted and to whom?), and processes of meaning construction about the protest (e.g., how was the protest tweeted?). 
The primary data collection task for this study involved assembling tweets relevant to the 15 October protest for Global Change in Italy. Concerning the first line of investigation (i.e., the positioning of the Italian \#15ott hashtag among other international hashtags before, during, and after the protest), a spreadsheet was created to gather quantitative information on the development of three hashtagged streams relevant to the protest (Hootsuite.com). The time-period covered by this part of the study is September 15 through November 15, 2011, that is, one month before and after the international day of action. Concerning the following three lines of investigations specifically focused on the use of the \#15ott Twitter stream after the protest (i.e., usage dynamics over time, players involved in networking versus news media mechanisms, and processes of meaning construction), 8,041 \#15ott hashtagged tweets were logged (Twapperkeeper.com). The time-period covered by this second part of the study is October 16 -November 15 2011, namely the first month following the protest. In sum, the study develops a quantitative analysis of longitudinal progression, networking mechanisms, and processes of meaning construction on Twitter streams.

\section{Analysis}

\subsection{Twitter Streams with reference to the 15 October Protest for Global Change: \#15ott, \#15oct, and \#15o}

Social media in general soon became the primary channel to gather information on the 15 October polycentric protest for Global Change. In particular, on Twitter two hashtags emerged as most prominent in preparation for, during, and after the demonstrations: the multilanguage \#15o and \#15oct hashtags. By mid-September, Twitter streams with reference to these two hashtags counted between 100 and 400 daily tweets. At the beginning of October they reached around 2,000 daily tweets. A specifically Italian stream started on October 7 under the new hashtag \#15ott, but only counted a relevant number of tweets (174) on the day prior to the protest, i.e., October 14.

Figure 1 shows the evolution of the streams with reference to the three mentioned hashtags (i.e., \#15o, \#15oct, and \#15ott) over a two-month period, from September 15 to November 15. It shows that the international \#15o hashtagged stream was the most popular one prior to, during, and after the protest. All three hashtagged streams reached a pick of tweets on the first day after the protest, i.e., on October 16. In fact, on that day, \#15o counted almost 60,000 tweets, \#15oct reached almost 22,000 tweets and \#15ott counted almost 10,000 tweets. Hence, overall, the three Twitter streams followed the same trend over the two-month period. Yet, by looking at the percentages of tweets posted per day in each stream over that same period, we can raise a new set of interesting considerations. 
Figure 1: Absolute number of tweets posted daily under hashtags \#15o, \#15oct, and \#15ott (September 15 - November 15, 2011)

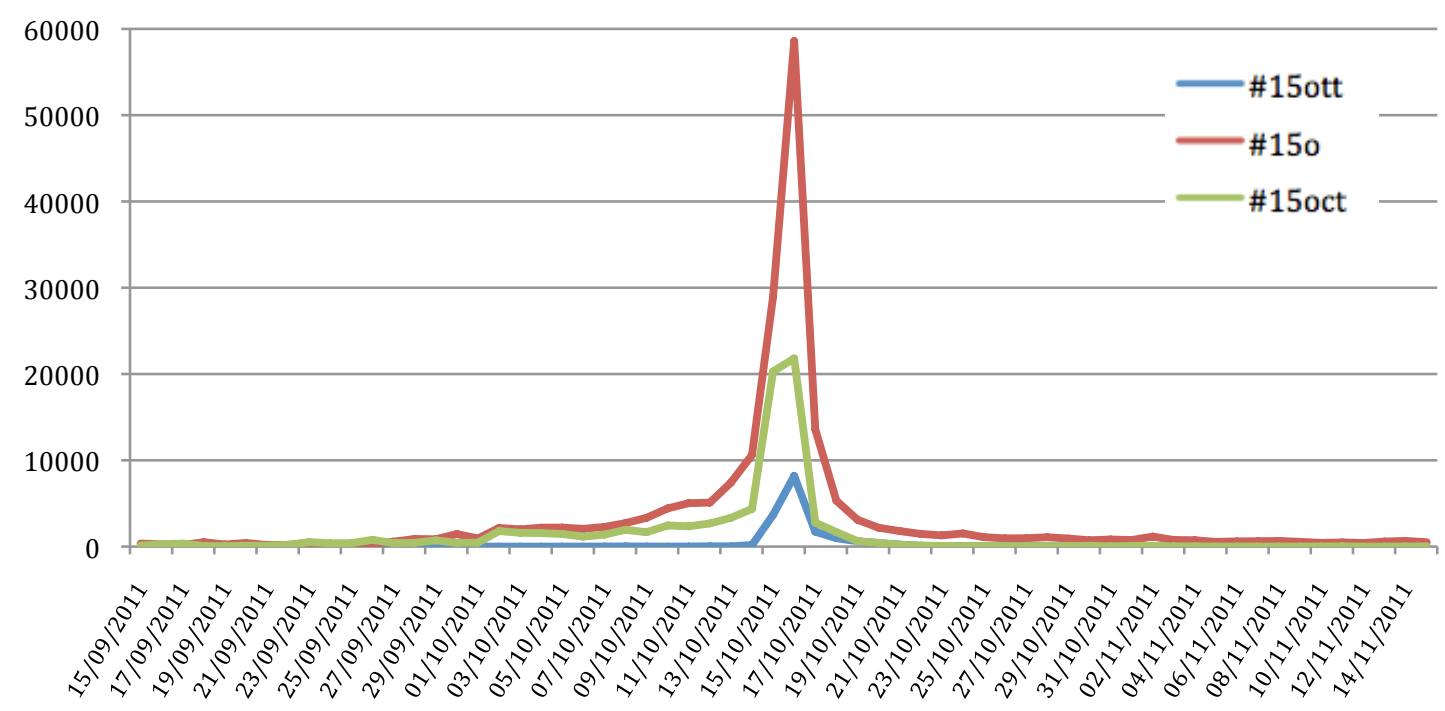

Source: Hootsuite.com

Figure 2: Daily percentage of tweets posted in hashtags \#15o, \#15oct, and \#15ott (over total number of tweets posted in each hashtag from September 15 to November 15, 2011)

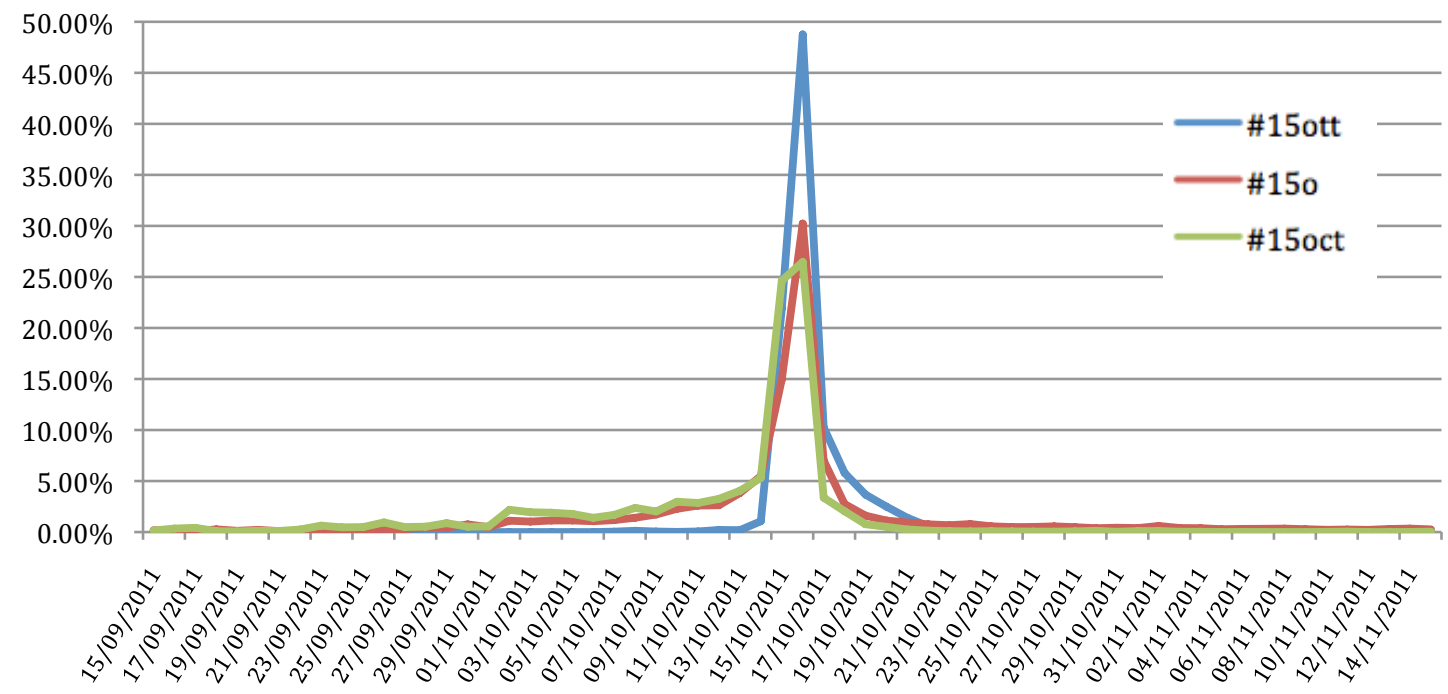

Source: Hootsuite.com 
Figure 2 clearly shows the underlying difference between the Italian \#15ott hashtagged Twitter stream and the Twitter streams marked with the international hashtags $\# 150$ and \#15oct. In fact, almost $60 \%$ of the Twitter stream related to the Italian chapter of the protest occurred in the first two days following the events, as compared to around $37 \%$ of the tweets in the \#15oct stream and around $30 \%$ of the tweets in the \#15o stream. This means that the Italian Twitter stream was almost exclusively used to discuss the outcomes of the domestic demonstration rather than for organizing and mobilizing purposes - as in the case of the international streams. In fact, \#15ott turned into a participative stream when the protest became known to a wider domestic public, that is, when photos and shootings of the violent events where exposed on both new and mainstream national media channels.

The following part of the study specifically draws attention to what happened in the \#15ott hashtagged Twitter stream in the days following the protest. In fact, the analysis focuses on the 8,041 tweets posted under the \#15ott hashtag from the morning of October 16 to that of November 15 .

\section{2. \#15ott Twitter Stream: Longitudinal Progression}

By the mid-morning of October 16 all Italian TV channels had widely diffused images of the events, mainly street destruction perpetuated by hooded protesters, fires in several sites of the city of Rome, burning cars, protesters throwing "sanpietrini" (cobblestones) and fire extinguishers at police officers, police officers using tear gas canisters against protesters and finally strong clashes between protesters and the police. All major Italian daily newspapers had produced their first coverage of the events through editorials, reportages and first-person narrations. In other words, in the morning of October 16, the Italian public opinion had been widely exposed to the events. In fact, starting from that morning until November 15 a total of 2,495 twitterers took part in the revitalized \#15ott Twitter stream to discuss about the events.

Figure 3: Absolute number of daily tweets posted under hashtag \#15ott from the midmorning of October 16 to that of November 15, 2011. 


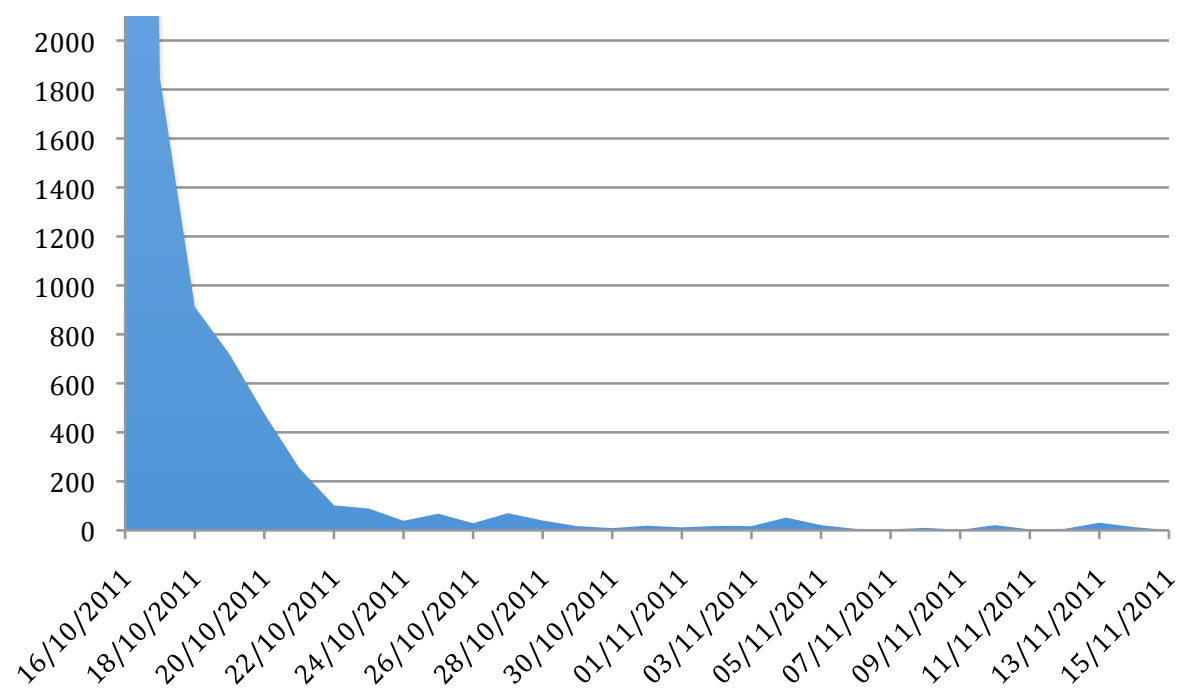

Figure 3 shows the portion of the \#15ott hashtagged Twitter stream investigated in the present and the following two sections. In line with other studies interested in conversational dynamics on social media, the analysis shows that the conversation was particularly active in the first three days following the protest, until October 18, when the number of daily tweets was still around 1,000. Between October 18 and October 21 the figure progressively decreased from around 1,000 to around 200. After October 21, the absolute number of tweets per day constantly decreased, and by the end of October no more than 50 tweets were posted daily. This certainly shows two attributes of Twitter streams relevant to public reasoning and opinion making around protest events of strong impact for the general public. First, it provides evidence on the booming real-time usage of Twitter streams to discuss and comment on events relevant to the public opinion. Second, it shows that Twitter streams of this sort are not durable conversational and interactional tools. Let us now focus on stream players and structure.

\section{3. \#15ott Twitter Stream: Players, Networking Dynamics, and News Media Processes}

Overall, the \#15ott hashtagged Twitter stream was fairly participatory since $80 \%$ of the tweets under this hashtag were posted by $44 \%$ of its twitterers. Hence, the stream had a distributed, crowdsourced management, that is, no individual user controlled the overall development of the debate on the stream. But who engaged in the stream and how did she/he do so?

Interestingly enough, out of the ten top twitterers only two are collective actors: Zero81 and Global project. The former is a university collective from Naples (zer081.org) and the latter a multimedia platform developed by Italian media activists (globalproject.info). The 
remaining top players in the stream are individuals whose Twitter profiles do not indicate any direct affiliation to organizations or advocacy actors as such. However, by searching the Twapperkeeper archives ${ }^{\mathrm{Vi}}$, it was possible to retrieve information on their in other Twitter streams. In fact, all top individual twitterers involved in the \#15ott hashtagged Twitter stream also took part in several other streams more or less related to the transnational movement for Global Change. The most common hashtagged streams are those marked by the transnational \#ows and \#occupywallstreet but also \#occupy, \#occupytheworld, \#occupyboston, \#occupyphoenix, \#oppupyoakland. However, other three sets of streams are commonly participated by the \#15ott top twitterers: streams marked by \#egypt, \#tahir, and \#libya hashtags, hence discussions centered around the Arab spring; streams marked by the \#londonriots hashtag with reference to the August 2011 London riots, and streams hashtagged with the title of different Italian political or close-to-political TV programs, namely, \#serviziopubblico, \#annozero, and \#vieniviaconme. This information seems to raise a set of considerations on the profile of top twitterers in Twitter streams relevant to public reasoning on social contention. First, the most active twitterers tend to participate in other streams associated to similar mobilizations in non-domestic contextx. Second, as Segerberg and Bennet (2011: 199) suggest, Twitter is to be considered within the contemporary media ecology and not as a stand-alone interactive platform. In fact, politically active twitterers are also likely to exploit traditional mass media channels to collect information on and discuss about social contention and political issues in general.

Concerning in-stream networking mechanisms, the top ten conversations ${ }^{\mathrm{vii}}$ only involved 16 participants. These are mostly individual twitterers, a part from infofreeflow and occupybologna, the first being a collective media blog (infofreeflow.noblogs.org: online) and the latter the Bologna chapter of the OWS movement. The shape of such top interactions prevents one from describing real networking mechanisms cutting across the stream. In fact, only two of the involved players participated in more than one conversation. The lack of dialogical practices is also confirmed by the stream's retweeting and linking patterns. In fact, almost $44 \%$ of the sample is made of tweets retweeted by different players ${ }^{\text {viii }}$. This shows that Twitter users involved in public reasoning on the protest spent more efforts in re-posting tweets posted by other users than in talking to one another ${ }^{\mathrm{ix}}$. Concerning linking, $65 \%$ of the overall tweets outlinked to other sources of information. In sum, in the \#15ott hashtagged Twitter stream, conversational, retweeting and linking patterns show that Twitter streams focused on social contention are more likely to enact news media mechanisms rather than real networking processes between twitterers. In other words, they ease the amplification of specific protest issues (retweets) and the diffusion of alternative protest news (outlinks) but do not foster conversational dynamics among users (replies).

The following section will specifically focus on the processes of meaning construction underlying the \#15ott hashtagged Twitter stream. By looking at the content of the most relevant hashtags, linked external sources, and words within the stream, it will attempt to 
describe how the \#15ott stream became functional to structure a topically informed political debate around the Italian chapter of the October 15 protest for Global Change.

\section{4. \#15ott Twitter Stream: Meaning Construction Around Social Contention}

The use of additional hashtags in the \#15ott Twitter stream increased over time. By October 24 , the average was reached of over two additional hashtags per tweet. This indicates that the \#15ott stream ramified towards other Twitter streams, marked with old and new hashtags, that is, while the original stream shrank and lost ground over time, public reasoning around the events shifted towards more specific, narrowly focused Twitter streams ${ }^{x}$. But let us now specifically focus on the 10 top hashtags, which constitute $23 \%$ of the overall additional hashtagging, namely \#indignati, \#15o, \#napoli, \#roma, \#15oct, \#blackbloc, \#occupyrome, \#notav, \#indignados, and \#occupybologna.

Figure 4: \#15ott egonetwork with the 10 most frequent additional hashtags

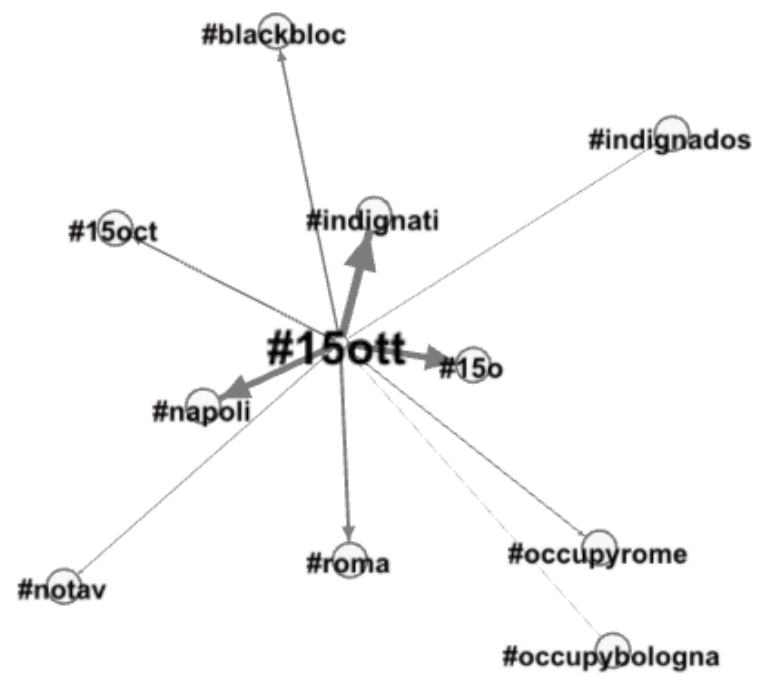

Figure 4 shows such top hashtags laid out as nodes of the \#15ott egonetwork. The nearer the hashtag and the thicker its tie to \#15ott, the more frequently it is mentioned in the \#15ott stream. The figure shows that we can identify three thematic layers of the conversation developed on this Twitter stream in relation to the Italian chapter of the 15 October protest. One layer develops along the positioning of the protest as part of a transnational reality. As said, the international hashtags \#15o and \#15oct, but also the originally Spanish \#indignados, transferred the conversation on the Italian demonstration within the debate around the transnational polycentric protest. Conversely, the second layer redirected the conversation towards specifically contingent events. In other words, hashtags like \#roma, \#napoli, and \#blackbloc bolstered the emergence of streams narrowly focused on factual events occurred 
on October 15 and the following days. \#roma, for instance, gathered tweets concerned with the Rome protest and its outcomes. \#napoli marked tweets dealing with police searches in Naples among activists involved in the Rome riots. \#blackbloc specifically centered the conversation on the identity of the hooded protesters who set the city of Rome on fire in the day of the protest.

The third thematic layer develops around the Italian collective actors more or less directly involved in the movement for Global Change, and therefore in the international action day of October 15. In fact, \#occupyrome and \#occupybologna tagged streams centered on the Rome and Bologna chapters of the Occupy Movement, respectively. Similarly, \#indignati marked those tweets concerned with the Italian chapter of the Indignados mobilization. The use of \#notav in the \#15ott stream is particularly interesting because it directly relates the long lasting Italian mobilization against the construction of the Turin-Lion TAV (high-speed rail system $)^{\mathrm{xi}}$ to the newborn movement for Global Change. This seems to suggest that in current public reasoning on social contention the most different actors tend to be framed as part of a common multi-issue and multi-level mobilization.

Let us now draw attention to the processes of meaning construction enacted by the extensive posting of hyperlinks to external sources of information ${ }^{x i i}$. In line with the results provided by Segerberg and Bennett (2011: 210), the analysis shows that the percentage of tweets containing links increased as the stream diminished in volume. Hence, twitterers increasingly pointed each other to different sources of online information, that is, they amplified the coverage of the protest by providing new alternative material for public reasoning. The 10 top external sources, which provide $42 \%$ of the overall hyperlinking instances, range from posts on personal blogs, to articles on online alternative media (i.e., peacereporter.it, looponline.info), on to columns published on online local newspapers (i.e., iltempo.it), twittered comic strips, posts by high-profile bloggers (i.e., Frankie.tv) and posts by low-profile bloggers. Two considerations need to be raised here: first, these top external sources of information are extremely varied in terms of genre, text, and reliability levels. Second, interestingly enough, none of them is related to any national mainstream media. Figure 5 maps the leading topics covered by such external sources of information. 
Figure 5: Leading topics in the top most linked external sources

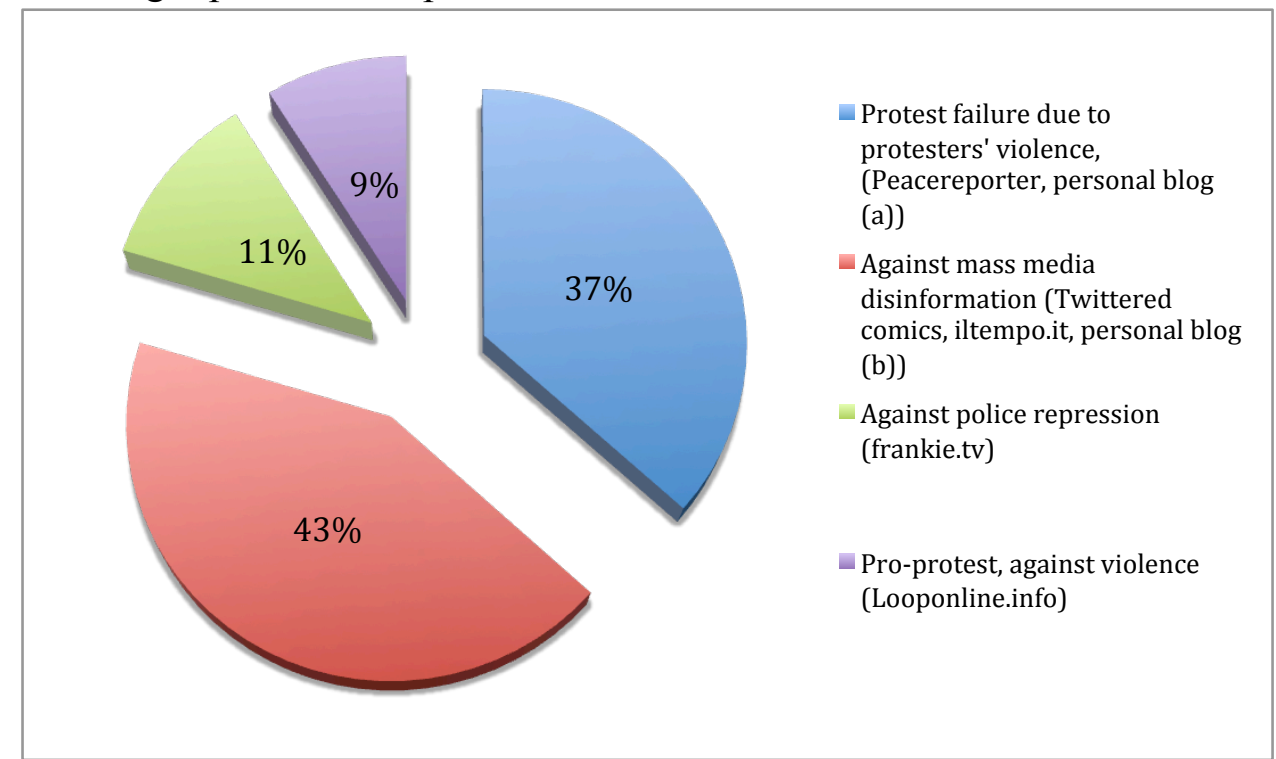

Four are the main topics differently dealt with by the mentioned external sources of information: the disinformation spread by the mass media in relation to the Rome protest on October $15(43 \%)$, the failure of the protest primarily due to the violence used by a conspicuous amount of participants (37\%), the repressive tactics of protest policing adopted by the police in the streets of Rome $(11 \%)$, and the importance of the protest despite the use of violence by part of the protesters $(9 \%)$. These thematic dynamics seem to be confirmed by the analysis of the top words used in the sampled tweets.

Figure 6: Tweets' word cloud (tagcrowd.com)

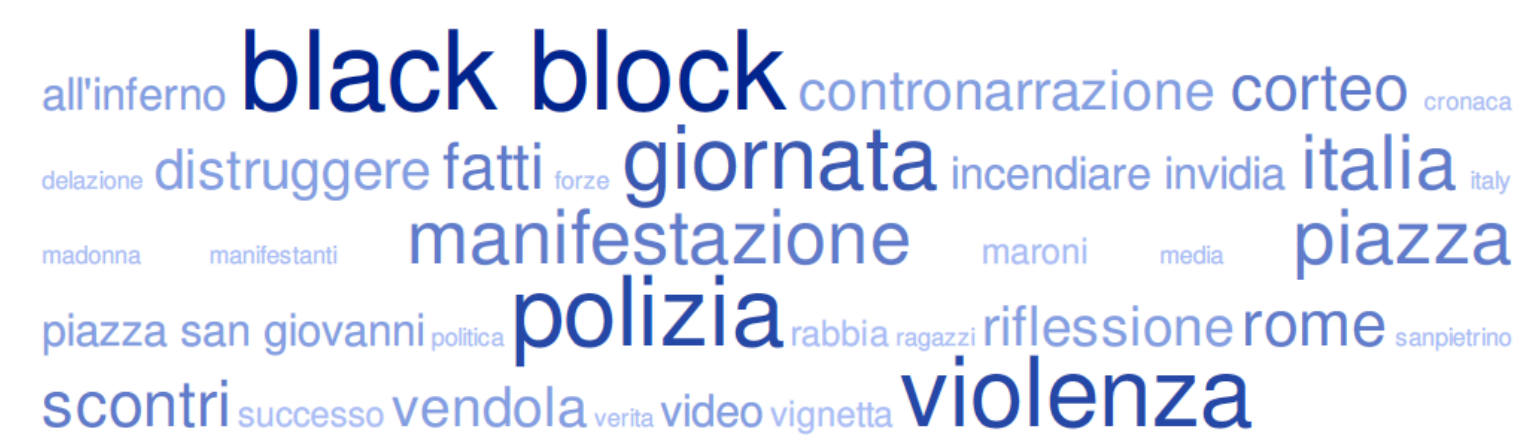

Figure 6 shows a word cloud of the 35 most frequent words used across the sample of tweets posted under the \#15ott Twitter stream. The bigger the word in the cloud, the more conspicuous its frequency ${ }^{x i i}$. The cloud shows that the texts posted by \#15ott twitterers was 
very much focused on the violent events occurred in Rome during the October 15 protest, with a special interest in the so-called Black Block group, who set the city on fire. The leading words black block, violenza and polizia, (black block, violence, and police) together with distruggere, scontri, all'inferno, rabbia, sanpietrino (to destroy, clashes, to hell, rage, cobblestone) provide evidence that in the days following the protest twitterers were primarily interested in discussing both protest violent tactics and the police's strategies of repression. Words like giornata, manifestazione, corteo, manifestanti, piazza, piazza San Giovanni, Italia and Italy (day, demonstration, rally, demonstrators, square, San Giovanni square, Italy) also grounded the discussion on the very events of October 15. Conversely, words like contronarrazione, cronaca, media, verità, video and vignetta (counter-narration, journalistic account, media, truth, shooting and comic strip) shifted the conversation on the coverage of the events by mainstream media. To conclude, words like maroni, vendola, and politica (Maroni $^{\mathrm{xiv}}$, Vendola ${ }^{\mathrm{xv}}$, and politics), reframed the stream in the institutional political context.

In sum, hashtags, hyperlinks, and textual outputs in the \#15ott Twitter stream all suggest that twitterers interested in discussing the Italian chapter of the October 15 protest for Global Change, enacted specific processes of meaning constructions around a series of relevant topics. Overall, data show that the stream fluctuated from more abstract issues, such as the positioning of the Italian mobilization within the transnational movement and the identification of the Italian local chapters of the protest, to more contingent issues like the violent events occurred in Rome and their outcomes and the biased coverage of the events by the mainstream media. Finally, part of the stream included elements of the institutional political context by recalling specific politicians involved in the commentary of the violent events in Rome.

\section{Conclusion}

The question of to what extent social media can bolster processes of democratization is central to current sociological discussions on transnational polycentric activism. While a measurement of the direct effects of social media usage on protest outcomes is of difficult resolution, the investigation of how social media are now entering protest ecologies can certainly provide interesting insight. By developing an exploratory analysis, this study specifically investigates the role of Twitter usage in processes of public reasoning and opinion formation in the aftermath of protest events. The central focus is on the Italian chapter of the October 15, 2011 polycentric protest for Global Change. The case study proves relevant for two reasons: the impact of the protest on the Italian public opinion, and the booming levels of Twitter activity registered in the country. The study is structured along four lines of investigation respectively focused on stream positioning, longitudinal progression, networking mechanisms, and processes of meaning construction 
By exploring the positioning of the Italian \#15ott Twitter stream among the corresponding international \#15o and \#15oct hashtagged streams, the first part of the analysis showed how the impact of the Rome riots of October 15 was mirrored by the booming Twitter activity on the day of the protest and the following three days. Such trend was not equaled in the two international streams taken for comparison. This suggests that at the local level, micro-blogging platforms may prove more functional to discuss protest events as they unravel on the streets and on mainstream media representations rather than for mobilizing and organizing purposes.

The following three lines of investigation specifically focused on the \#15ott stream. First, The analysis of the stream longitudinal progression showed that Twitter streams centered on domestic protest events are characterized by booming real-time usage and are not durable conversational and/or interactional tools. Second, by drawing attention to users and usage dynamics it was possible to ascertain that the top players in the stream were neither collective advocacy actors nor institutional organizations or news media channels. Most of the top players in the stream were individual twitterers already involved in streams centered on other informal transnational and/or local political debates. Moreover, the analysis of usage dynamics - in terms of conversational, retweeting and linking patterns - showed that public reasoning around social contention on micro-blogging platforms is more likely to enact news media mechanisms rather than real networking processes. This means that, while microblogging eases the emphasis on specific protest issues (via retweets) and the diffusion of alternative frames of protest (via outinks), it does not foster dialogical interactions among users (via replies).

Finally, the analysis of the underlying processes of meaning construction showed that in the \#15ott hashtagged Twitter stream public reasoning around the events shifted towards specific sub-topics via other hashtagged streams, via hyperlinks to external sources and via the use of specific keywords in the posts. Findings showed that not only the stream became functional to public reasoning around the traditional elements of mediatized protest, e.g., violence, drama, and spectacle. The \#15ott stream fostered the debate on at least five additional primary topics: the biased coverage of the events by the mainstream media, the relationships between the outcomes of the protest and the domestic institutional polity, the positioning of the Italian mobilization within the transnational movement for Global Change, and the identification of both the Italian local chapters of the movement for Global Change and the other domestic actors involved in local mobilizations. This proves that in microblogging settings public reasoning around social contention can successfully develop along protest representations originated outside of the traditional hubs of news media production.

In sum, emerging micro-blogging settings may foster public reasoning around social contention by providing alternative, user-generated, representations of protest, able to involve expanding and varied publics. However, as of today, Twitter and the like seem to work more as news media rather than truly interactional platforms for dialogical public sphere dynamics. 
In specific terms, individuals interested in discussing social contention use micro-blogging platforms to engage in the mediatization of dissent, that is, they enhance the debate of specific protest issues and develop protest themes aligned to or diverging from those covered by the mainstream media. What is still to be ascertained is how Twitter streams can affect the levels of specifically interactional processes of public reasoning - typical of actual deliberative democracy - and, eventually, enhance traditional and less traditional forms of active political participation.

\section{Endnotes}

${ }^{i}$ The 2011 GlobalWebIndex report on social media adoption in Italy shows that in 2011 11\% of the Italian population used micro-blogging platforms. In specific terms, the study shows that, while other EU countries had higher micro-blogging usage rates, Italy had the fastest growth in micro-blogging usage.

ii The OWS movement officially started in September 17, 2011 with the occupation of Zuccotti Park in New York City.

${ }^{\text {iii }}$ Popolo Viola (Purple people) is a social movement emerged in Italy in October 2009, with the main purpose to call for the resignation of the then Italian Prime Minister Silvio Berlusconi. Since 2009, Popolo viola has organized several polycentric protests all over Italy, with its leading chapter remaining in the city of Rome.

iv The label 'Black Block' has been traditionally used to identify clusters of anarchist affinity groups declaredly open to police confrontation, blockades and property destruction. They usually wear black clothing and masks (Fernandez 2008: 58-59).

${ }^{\mathrm{v}}$ Indymedia would become an internationally diffused network for the alternative coverage of protest events for global justice in the 2000s.

${ }^{v i}$ Twapperkeeper was a public online system that allowed one to generate tweet archives on the basis of user-generated searches. Twapperkeeper shut down in December 2011.

${ }^{\text {vii }}$ Twitter conversation are here understood as exchanges of at least one @reply or mention in each direction between any two twitterers.

viii Given the crowdsourced management pattern characterizing the stream, it is difficult to define this dynamic as a gatekeeping process. Perhaps, the only case in which the stream was being manipulated occurred on October 20, when two players constantly retweeted a tweet posted by zero81, generating over 700 retweets.

${ }^{\text {ix }}$ Kwak et al. (2010: 10)'s study shows that in Twitter reasoning around social contention "once retweeted, a tweet gets retweeted almost instantly on the $2 \mathrm{nd}$, 3rd, and 4th hops away from the source, signifying fast diffusion of information after the 1st retweet"

${ }^{x}$ Overall, the sample contains 16,305 instances of additional hashtags.

${ }^{x i}$ No Tav is an Italian social movement active since 2002. Its main goal is to oppose the construction of the Turin-Lion high-speed rail system. The reasons behind this opposition are related to the environmental and economic impact that such rail system would have on the territory (Comitato NoTav - Torino: online). 


\footnotetext{
xii The sample contains 5,244 occurrences of hyperlinks. However, one of the top links is an URL retweeted 729 times on the same day by two only users, hence it was excluded from the analysis.

xiii The cloud was created by excluding the most common words in the Italian vocabulary, along with hashtags and Twitter usernames.

${ }^{x i v}$ Roberto Maroni was the then Italian Minister of the Interior.

${ }^{\mathrm{xv}}$ Nichi Vendola is the leader of Sinistra Ecologia e Libertà, an Italian left-wing political party.
}

\section{References}

15October.net (2011). More than 1,000 cities - 82 countries. Available at: http://15october.net (accessed 10 May 2012).

Bajpai K and Jaiswal A (2011) A Framework for Analyzing Collective Action Events on Twitter. In: Proceedings of the $8^{\text {th }}$ International ISCRAM Conference. Lisbon, Portugal, May.

Bernardi Bifo, F. (2011). Mantra del sollevarsi (15 Ottobre e dintorni) Loop, 18 October. Available at: http://www.looponline.info/index.php/component/content/article/644mantra-del-sollevarsi-15-ottobre-e-dintorni (accessed 10 May 2012).

Castells M (1996) The Rise of the Network Society. Oxford: Blackwell.

Comitato NoTav - Torino. Chi siamo. Available at: http://www.notavtorino.org/ (accessed 10 May 2012).

Cottle S (2006) Mediatized Conflict. Maidenhead: Open University Press.

Cottle S (2011) Transnational Protests and the Media. New Departures, Challenging Debates in Cottle S and Lester L Transnational Protests and the Media. New York: Peter Lang.

Dell'Orefice F (2011) L'infiltrato? "Sono io: Di Chio". Il Tempo, 17 October. Available at: http://www.iltempo.it/politica/2011/10/17/1293742uomo nero.shtml\#.Tpv06jmuyCr.twitter (accessed 10 May 2012).

Downey J and Fenton N (2003) New Media, Counter Publicity and the Public Sphere. New Media and Society 5: 185- 202.

Fernandez LA (2008) Policing Dissent. Social Control and the Anti-Globalization Movement. Piscataway: Rutgers University Press.

Garrido M and Halavais A (2003) Mapping Networks of Support for the Zapatista Movement in McCaughey M and Ayers M D (eds.). Cyberactivism: Online Activism in theory and practice. New York: Routledge, pp. 165-184.

Gitlin T (1980) The Whole World is Watching. Mass Media in the Making and Unmaking of the New Left. Berkeley: University of California Press.

GlobalWebIndex (2011) Social Media Adoption in Italy. Available at www.globalwebindex.net (accessed 10 May 2012).

Halloran J Elliott P and Murdock G (1970) Demonstrations and Communication: A Case 
Study. London: Penguin.

Howard PN, Agarwal SD and Hussain MM (2011) When Do States Disconnect Their Digital Networks? Regime Responses to the Political Uses of Social Media. The Communication Review 14: 216-232.

Huberman B, Romero D and Wu F (2009) Social networks that matter: Twitter under the microscope. First Monday 14 (1). Available at: http://www.hpl.hp.com/research/scl/papers/twitter/twitter.pdf (accessed 10 May 2012).

Corriere della sera.it (2011) Indignati, 12 arresti e 8 denunce: tra loro una minorenne e 2 donne.

Available

at: http://roma.corriere.it/roma/notizie/cronaca/11 ottobre_16/indagini-polizia-blackbloc1901838843449.shtml (accessed 10 May 2012).

Frankie hi-nrg (2011). Forse dell'ordine Available at: http://www.frankie.tv/Default.aspx?PG=Home (accessed 10 May 2012).

Kwack H, Lee C, Park H and Moon S (2010) What is Twitter, a Social Network or a News Media? In: $W W W$ 2010, April 26-30.

Langman L (2005) From Virtual Public Spheres to Global Justice: A Critical Theory of Internetworked Social Movements. Sociological Theory 23(1): pp. 42-74.

Murdock G (1981) Political Deviance: The Press Presentation of a Militant Mass Demonstration in Cohen S and Young J (eds) The manufacture of News - Deviance, Social Problems and the Mass Media. London: Constable, pp. 206-225.

Peacereporter (2011). Indignados, un fallimento tutto italiano, 15 October. Available at: http://it.peacereporter.net/articolo/31028/Indignados, + un + fallimento+tutto + italiano (accessed 10 May 2012).

Procter R, Vis F and Vox A (2011) Reading the Riots. Guardian. Available at: http://www.guardian.co.uk/uk/interactive/2011/dec/07/london-riots-twitter (accessed 10 May 2012).

Segerberg A and Bennet WL (2011) Social Media and the Organization of Collective Action: Using Twitter to Explore the Ecologies of Two Climate Change Protests. The Communication Review 14(3), 197-215.

Villeard Ford T and Gil G (2001) Radical Internet Use in Downing, J D H (Ed.): Radical Media. London: Sage.

Waddington D (1992) Media representation of Public Disorder in Waddingston D (ed.) Contemporary Issues in Public Disorder. London: Routledge, pp. 160-178.

Zero81 (2011). Contro la repressione, uniti si vince, 20 October. Available at: http://www.zer081.org/2011/10/20/napoli-comunicato-contro-le-perquisizioni-post-15ottobre/ (accessed 10 May 2012).

\section{Other Web Sources}


Facebook community 15 ottobre: un milione di indignati in corteo verso il parlamento, available at https://www.facebook.com/15OTTOBRE (accessed 10 May 2012).

Facebook event Echte Demokratie Jetzt, available at: https://www.facebook.com/event.php?eid=157195821014727 (accessed 10 May 2012).

Facebook event Revolución global: Democracia real $Y$, available at: http://www.facebook.com/event.php?eid=228595710495676 (accessed 10 May 2012).

Facebook event Révolution Mondiale pour une Réelle Démocratie avaiable at: http://www.facebook.com/event.php?eid=228132803873978 (accessed 10 May 2012).

Infofreeflow. Available at: www.infofreeflow.noblogs.org (accessed 10 May 2012). 